\title{
A STUDY ON KNOWLEDGE, ATTITUDES, AND PRACTICES FOR THE PREVENTION OF DIABETIC FOOT IN RURAL TERTIARY CARE TEACHING HOSPITAL
}

\author{
GOPAL TELI*, B. G. PONNAPPA \\ Department of Surgery, Adichunchanagiri Hospital and Research Center, B. G. Nagara 571448, Karnataka, India \\ Email: drgopalt@gmail.com
}

Received: 19 May 2017 Revised and Accepted: 13 Jul 2017

\section{ABSTRACT}

Objective: To assess the knowledge, attitude, and practice of diabetic patients regarding care of their own feet.

Methods: This is a cross-sectional study conducted in the inpatient department of surgery at Adichunchanagiri hospital and research centre, B. G. Nagara, Karnataka, India from $1^{\text {st }}$ Nov. 2016 to $31^{\text {st }}$ Dec. 2016. The relation between gender and knowledge, attitude and practices of people with diabetes patients were compared by using the Chi-square test at $95 \%$ confidence interval at $\mathrm{p}<0.05$.

Results: Out of 51 patients, $72.54 \%$ were male and $27.46 \%$ female and $45.1 \%$ of the patients were in the age range $61-80$ y. The mean SD of the age was $60.49 \pm 14.02$. The mean SD of body weight of the patient was $66.17 \pm 8.54$. The majority of the patients $45.1 \%$ were farmers and $41.7 \%$ were illiterate. Most of them did not know the practice of correct foot hygiene (39.22\%) and what abnormalities observe in their feet (66.67\%). We found that $90.2 \%$ patients were engaged in foot self-care practice and more than half of them (54.1\%) always inspected their footwear before using it. Interestingly, more women were involved in foot care $(100 \%)$ as compared to men $(86.46 \%)$ but statistically not significant ( $\mathrm{p}=0.147$ )

Conclusion: We found that patients were not having sufficient knowledge about the correct hygiene of the foot, what abnormalities to observe in their feet and about ideal footwear. Even though females were showing interest towards self-care examination and foot care practice, it is essential that all the diabetic patients must be educated about the knowledge, attitude and foot self-care practice to prevent diabetic foot related complications.

Keywords: Diabetes, Diabetic foot, Knowledge, Attitude, Practice and cross-sectional study

(C) 2017 The Authors. Published by Innovare Academic Sciences Pvt Ltd. This is an open access article under the CC BY license (http://creativecommons.org/licenses/by/4.0/) DOI: http://dx.doi.org/10.22159/ijpps.2017v9i9.20114

\section{INTRODUCTION}

Currently, there are an estimated 366 million people affected with diabetes mellitus globally and India is estimated to have 61.3 million diabetics, which is projected to cross 100 million by the year 2030 [1].

Diabetes mellitus is a disease known for its multifaceted complications and foot ulceration, which often results in lower extremity amputations which is one of the most common complications associated with the disease [3]. The prevalence of diabetic foot ulcers among outpatient and inpatient diabetics in a rural Indian study was found to be $10.4 \%$ [1]. Diabetic foot ulcers frequently become infected and are a major cause of hospital admissions [2]. They also account for more than half of non-traumatic lower limb amputations in this patient population [3]. It has been shown that $49-85 \%$ of all diabetic foot related problems are preventable if appropriate measures are taken and can be achieved through a combination of good foot care, provided by a multidisciplinary diabetes care team, and appropriate education for both, people with diabetes and healthcare professionals [4]. All patients with diabetes are potentially at risk of diabetic foot, which can only be avoided by creating awareness about the importance of appropriate self-care [2]

Preventive and prophylactic foot care has been advocated to decrease patient morbidity, utilization of expensive resources, as well as the risk for amputations [5]. This includes identification of risk factors, patient education, and intensive podiatric care and has shown to be both cost-effective and cost-saving $[3,6]$.

The present study aims to assess the knowledge, attitude, and practice of diabetic patients as regards care of their own feet.

\section{MATERIALS AND METHODS}

This was a cross-sectional, unicentric study conducted on the inpatients in the department of Surgery at Adichunchanagiri hospital and research centre, B. G. Nagara, Karnataka, India, from $1^{\text {st }}$ Nov. 2016 to $31^{\text {st }}$ Dec. 2016 and a total of 51 patients were enrolled. The patients were informed about the study and those who showed interest participated by providing their written consent. The required details were collected in a well-designed data collection form, which consists of patient demographic details, social and medical history, presenting illness and foot care habits.

The collected data were analyzed by using appropriate statistical tests. The relation between gender and knowledge, attitude and practices of diabetes patients were compared by using the Chi-square test at $95 \%$ confidence interval at $p<0.05$. Data were expressed as mean with SD and Chi-square test used to find the level of significance.

\section{RESULTS}

Table 1, showed that out of 51 patients, $72.54 \%$ were male and $27.46 \%$ were female and $45.1 \%$ of the patients were in the age range $61-80 \mathrm{y}$. The mean SD of age was $60.49 \pm 14.02$. The mean SD of body weight of the patient was $66.17 \pm 8.54$. Majority of the patients $45.1 \%$ were farmers and $41.7 \%$ were illiterate, $23.53 \%$ were having co-morbidities, $11.76 \%$ were having a family history of diabetes, $41.17 \%$ were having a history of diabetes of less than $5 \mathrm{y}$ and $19.62 \%$ patients had a history of diabetes of more than $10 \mathrm{y}$.

Information regarding the patients knowledge regarding foot care (table 2) revealed that $39.22 \%$ did not know correct foot hygiene practice, $45.1 \%$ stated that they do not know about ideal foot drying, $66.67 \%$ did not know what a person with diabetes should observe in their feet, and only 5.88\% answered that comfortable and closed footwear is ideal. As regards nail care, $50.98 \%$ knew how to cut their nails correctly.

In terms of attitudes to prevent foot ulcers (table 3), most of the patients $(62.75 \%)$ would put physical examination of the foot into practice if they received the necessary information to prevent 
foot-related complications. When asked if they would engage in self-foot care practices $90.2 \%$ answered positively. Moisturizers were used by $(3.92 \%)$ and various oils by $(66.67 \%)$ to prevent their feet from becoming dry (85.29\%) on a daily basis as part of foot care.

Regarding foot care to prevent chronic foot complications (table 4), $100 \%$ stated washing, $64.7 \%$ drying, $43.5 \%$ moisturizing; and $34.1 \%$ massaging feet is needed. In terms of the most frequently used footwear, $87.1 \%$ used open sandals, and more than half stated they always inspected their footwear before use (54.1\%). When asked about the habit of cutting their nails, $(91.8 \%)$ answered positively, (75.6\%) cut their nail in a rounded shape using a pointed-tip scissors (46.2\%).

Table 5 shows the analysis of knowledge, attitudes, and practices in relation to gender. Results showed that men statistically had more knowledge on the right footwear to use and out of 37 men, 3 men wore comfortable and closed footwear, but 26 men were using other types of footwear but statistically not significant $(\mathrm{P}=0.890)$. Women showed they were more willing to include self-care practices in their routine $(\mathrm{P}=0.147)$. When it comes to foot care, $100 \%$ patients were washing their feet on a regular basis and females were interestingly involved in moisturizing (85.72\%) and massaging (64.28\%) their feet as compared to males, but statistically not significant $(\mathrm{P}=0.131)$.

Table 1: Demographic details of the patients

\begin{tabular}{|c|c|c|}
\hline Variables & Number & $\%$ \\
\hline \multicolumn{3}{|l|}{ Gender } \\
\hline Male & 37 & 72.54 \\
\hline Female & 14 & 27.46 \\
\hline \multicolumn{3}{|l|}{ Age range } \\
\hline $20-40$ & 4 & 7.84 \\
\hline $41-60$ & 20 & 39.22 \\
\hline $61-80$ & 23 & 45.10 \\
\hline$>80$ & 4 & 7.84 \\
\hline \multicolumn{3}{|l|}{ Weight range } \\
\hline $20-40$ & 0 & 0 \\
\hline $41-60$ & 12 & 23.53 \\
\hline $61-80$ & 35 & 68.62 \\
\hline$>80$ & 4 & 7.85 \\
\hline \multicolumn{3}{|l|}{ Occupation } \\
\hline Employed & 2 & 3.93 \\
\hline Unemployed & 18 & 35.29 \\
\hline Farmer & 23 & 45.10 \\
\hline Business & 8 & 15.68 \\
\hline \multicolumn{3}{|l|}{ Education } \\
\hline Illiterate & 21 & 41.17 \\
\hline Primary & 24 & 47.05 \\
\hline Secondary & 5 & 9.82 \\
\hline PUC & 0 & 0 \\
\hline Degree & 1 & 1.96 \\
\hline \multicolumn{3}{|c|}{ Smoking history } \\
\hline Smoker & 4 & 7.85 \\
\hline Past smoker & 24 & 47.05 \\
\hline Non smoker & 23 & 45.10 \\
\hline \multicolumn{3}{|c|}{ Alcoholic history } \\
\hline Alcoholic & 3 & 5.88 \\
\hline Past alcoholic & 21 & 41.17 \\
\hline Non-alcoholic & 27 & 52.95 \\
\hline \multicolumn{3}{|l|}{ Family History } \\
\hline Yes & 6 & 11.76 \\
\hline No & 45 & 88.24 \\
\hline \multicolumn{3}{|c|}{ Duration of diabetes } \\
\hline$<5$ & 21 & 41.17 \\
\hline $05-10$ & 20 & 39.21 \\
\hline$>10$ & 10 & 19.62 \\
\hline
\end{tabular}

Table 2: Knowledge of diabetes on preventive foot care of diabetic patients

\begin{tabular}{|c|c|c|}
\hline Variables & Number $(\mathrm{N}=51)$ & $\%$ \\
\hline \multicolumn{3}{|l|}{ Correct hygiene } \\
\hline - With cold water and regular soap & 11 & 21.56 \\
\hline - With cold water only & 12 & 23.52 \\
\hline - With warm water and neutral soap & 8 & 15.68 \\
\hline - I don't know & 20 & 39.22 \\
\hline \multicolumn{3}{|l|}{ Ideal drying } \\
\hline - With a towel, without drying between the toes & 13 & 25.49 \\
\hline - With a towel, drying between the toes & 9 & 17.64 \\
\hline - $\quad$ No need to dry & 6 & 11.76 \\
\hline - I don't know & 23 & 45.1 \\
\hline \multicolumn{3}{|l|}{ Observing your feet } \\
\hline - $\quad$ Only when there is callosity, tingling and numbness & 7 & 13.73 \\
\hline - $\quad$ Coloration, temperature, blisters, callosity, wounds, tingling and numbness & 2 & 3.92 \\
\hline - $\quad$ No need to observe feet & 8 & 15.68 \\
\hline
\end{tabular}




\begin{tabular}{|c|c|c|}
\hline - I don't know & 34 & 66.67 \\
\hline \multicolumn{3}{|l|}{ Ideal Footwear } \\
\hline - $\quad$ Tight & 1 & 1.96 \\
\hline - Loose & 2 & 3.93 \\
\hline - Comfortable and closed & 3 & 5.88 \\
\hline - Comfortable and open & 11 & 21.56 \\
\hline - Any type & 24 & 47.05 \\
\hline - I don't know & 10 & 19.60 \\
\hline \multicolumn{3}{|l|}{ Correct Nail Cutting } \\
\hline - $\quad$ Rounded & 26 & 50.98 \\
\hline - $\quad$ Straight & 2 & 3.93 \\
\hline - $\quad$ Either rounded or straight & 4 & 7.84 \\
\hline - I don't know & 20 & 39.22 \\
\hline
\end{tabular}

Table 3: Attitudes towards preventing diabetic foot ulcers of patients

\begin{tabular}{|c|c|c|}
\hline Variables & Number & $\%$ \\
\hline \multicolumn{3}{|l|}{ Would perform a physical examination } \\
\hline - Yes & 32 & 62.75 \\
\hline - $\quad$ No & 19 & 37.25 \\
\hline Why perform a physical examination & 27 & 81.25 \\
\hline $\begin{array}{l}\text { - To prevent foot related complications } \\
\text { - To detect changes in the feet }\end{array}$ & 6 & 18.75 \\
\hline \multicolumn{3}{|l|}{ Would engage in self-care } \\
\hline - Yes & 46 & 90.2 \\
\hline - $\quad \mathrm{No}$ & 5 & 9.8 \\
\hline Why engage in self-care & 37 & 78.72 \\
\hline $\begin{array}{l}\text { - To prevent foot related complications } \\
\text { - To detect changes in the feet }\end{array}$ & 10 & 21.28 \\
\hline \multicolumn{3}{|l|}{ Would Use Moisturizer } \\
\hline - $\quad$ Yes & 2 & 3.92 \\
\hline - $\quad$ No & 49 & 96.08 \\
\hline Why Use Moisturizer & 1 & 50 \\
\hline $\begin{array}{l}\text { - } \quad \text { To prevent feet from getting dry } \\
\text { - } \quad \text { To ensure good appearance of feet }\end{array}$ & 1 & 50 \\
\hline \multicolumn{3}{|l|}{ Would Use Oil } \\
\hline - Yes & 34 & 66.67 \\
\hline - $\quad$ No & 17 & 33.33 \\
\hline Why use oil & 29 & 85.29 \\
\hline $\begin{array}{l}\text { - To prevent feet from getting dry } \\
\text { - } \quad \text { To ensure good appearance of feet }\end{array}$ & 5 & 14.71 \\
\hline
\end{tabular}

Table 4: Foot care practices performed by diabetic patients

\begin{tabular}{|c|c|c|}
\hline Variables & Number & $\%$ \\
\hline \multicolumn{3}{|l|}{ Foot care } \\
\hline - Wash & 51 & 100 \\
\hline - $\quad$ Dry & 43 & 84.30 \\
\hline - $\quad$ Oil & 34 & 66.67 \\
\hline - $\quad$ Massage & 17 & 33.03 \\
\hline \multicolumn{3}{|c|}{ Types of habitually used footwear } \\
\hline - Closed and tight & 2 & 3.92 \\
\hline - $\quad$ Open sandals & 43 & 84.31 \\
\hline - Closed and soft & 6 & 11.77 \\
\hline \multicolumn{3}{|c|}{ Inspect footwear before use } \\
\hline - Always & 9 & 17.64 \\
\hline - $\quad$ Sometimes & 20 & 39.22 \\
\hline - $\quad$ Rarely & 16 & 31.37 \\
\hline - $\quad$ Never & 6 & 11.77 \\
\hline \multicolumn{3}{|l|}{ Nail cutting } \\
\hline - Yes & 47 & 92.16 \\
\hline - $\quad$ No & 4 & 7.84 \\
\hline \multicolumn{3}{|l|}{ Nail cut } \\
\hline - $\quad$ Rounded & 26 & 50.98 \\
\hline - $\quad$ Straight & 2 & 3.93 \\
\hline \multicolumn{3}{|l|}{ Cutting instrument } \\
\hline - $\quad$ Pointed tip scissor & 1 & 1.96 \\
\hline - $\quad$ Cutter or pen knife & 2 & 3.92 \\
\hline - $\quad$ Rounded tip scissor & 2 & 3.92 \\
\hline - $\quad$ Nail cutter & 46 & 90.20 \\
\hline
\end{tabular}


Table 5: Relation between gender and knowledge, attitude and practices of people with diabetes patients

\begin{tabular}{|c|c|c|c|}
\hline Variables & Male (37) & Female (14) & $\mathbf{P}^{*}$ value \\
\hline \multicolumn{4}{|l|}{ Types of footwear } \\
\hline - $\quad$ Tight & $1(2.7 \%)$ & $0(0 \%)$ & 0.890 \\
\hline - Loose & $1(2.7 \%)$ & $1(7.1 \%)$ & \\
\hline - $\quad$ Comfortable and closed & $2(5.4 \%)$ & $1(7.1 \%)$ & \\
\hline - Comfortable and open & $6(16.2 \%)$ & $5(35.7 \%)$ & \\
\hline - Any type & $16(43.24 \%)$ & $9(64.28 \%)$ & \\
\hline - I don't know & $7(18.92 \%)$ & $3(21.42 \%)$ & \\
\hline \multicolumn{4}{|l|}{ Would perform self-care } \\
\hline - Yes & $32(86.48 \%)$ & $14(100 \%)$ & 0.147 \\
\hline - $\quad$ No & $5(13.5 \%)$ & $0(0 \%)$ & \\
\hline \multicolumn{4}{|l|}{ Foot care } \\
\hline - Wash & $37(100 \%)$ & $14(100 \%)$ & 0.131 \\
\hline - $\quad$ Dry & $33(89.18 \%)$ & $10(71.43 \%)$ & \\
\hline - $\quad$ Moisturize & $22(59.46 \%)$ & $12(85.72 \%)$ & \\
\hline - $\quad$ Massage & $8(21.62 \%)$ & $9(64.28 \%)$ & \\
\hline
\end{tabular}

\section{DISCUSSION}

In this study, we found that male patients (72.54\%), age range 61-80 y $(45.10 \%)$ and weight range $61-80 \mathrm{~kg}(68.62 \%)$ were mostly affected. Most of the patients were farmers, unemployed, illiterate, non-smoker and non-alcoholic [3]. In this survey, it showed that most of the patients were ignorant about the care of feet and did not have knowledge about correct foot hygiene, ideal drying method, how to observe feet for complications and about ideal footwear. Results from a similar study showed $39.22 \%, 45.1 \%$, and $66.67 \%$ did not know about correct hygiene, ideal drying and observing foot respectively [7]. Most of the patients showed a good attitude about the foot self-care but they did not have much knowledge about it. A study conducted in Italy showed that more than $50 \%$ of the patients reported that they had not had their feet examined by their physician and $28 \%$ said that they had not received foot care education $[8,9]$. Shah et al. noted that the feet of only one-third of diabetic patients $(34.43 \%)$ are being regularly examined by primary health care physicians. However, most patients admitted receiving health education by their family physicians (85.29\%) [10]. 17.64\% patients inspected their footwear before using it. Most of them answered about the correct way of nail cutting (96.07\%) and using proper nail cutting instrument (nail cutter 90.2\%). They did not have any idea about the types of footwear to be used (any types $47.05 \%$ ). As the patient himself/herself plays the crucial role in the prevention of diabetic foot disease, education on foot care is important [11].

It was also observed that there was a predominance of women regarding knowledge and practice of foot care in relation to men, which could be explained by the fact that women are more concerned with health, had a greater perception of the disease and used the health service more often. This finding is not considered a new fact and is in line with other studies on similar topics [8-11]. With regard to gender and knowledge, attitude and practices of people with diabetes mellitus to prevent diabetic foot ulcer, females were more engaged with foot care by using correct hygiene, inspecting foot, nail cutting and types of footwear used. The use of customized shoes reduced the development of new foot ulcers from $58 \%$ to $28 \%$ over one year of follow-up in a report [12].

Females were taking more care about their feet by using moisturizer and oils as compared to males, but statistically not significant $(p=0.131)$. Sex has shown no relationship regarding knowledge and practices of foot care [2]. But in a study conducted in India, it was shown that low scores for foot care knowledge were more common in women $(78.5 \%)$ than in men $(62.5 \%)$ [11]. Whereas in another study, multivariate analysis showed that age, years of schooling and sex were an independent determinant of the knowledge score in the respondents with type 2 Diabetes [13].

In our study, most of the patients were having poor knowledge in foot care practices and this view was also supported by the Nigerian and Pakistani studies where one-third to half of the patients were found to have poor foot care practices $[13,14]$. One of the most common reasons for neglect in foot care practice was that most of the patients were illiterate and with low education. Similar findings were seen in Iranian and Pakistani studies $[14,15]$. The association between low educational status as well as low diabetes awareness level was found with the poor practice of diabetic foot care, similar to another Pakistan study [10]. This suggests that education determines knowledge, awareness as well as the practice of foot care by diabetic patients [1].

\section{LIMITATION}

A small number of interviewees because of the short period of time and inability to reassess the knowledge, attitude, and practices to prevent diabetic foot after educating them are the limitations of this study.

\section{CONCLUSION}

The knowledge, attitude and practices of study participants on foot care to prevent diabetic foot ulcer were not sufficient. The result showed that patients had a good attitude towards self-care and self-examination of the foot. But with regard to practice, results showed that some patients were involved in self-care practices that are not sufficient, which could be related to a lack of knowledge. The knowledge, attitude and practices triad must be interconnected in order to achieve successful preventive foot care. After seeing the results it appears that it is mandatory to educate all the diabetic patients regarding knowledge, attitude, and practice to prevent diabetic foot

\section{AUTHORS CONTRIBUTION}

Dr. Gopal Teli, who conducted the study, collected data, reviewed literature and wrote the manuscript and done statistics.

Dr. B. G. Ponnappa contributed to research concept development, topic selection, questionnaire development and guided the research process and manuscript preparation.

\section{ACKNOWLEDGEMENT}

Authors sincerely and wholeheartedly convey their gratitude to entire medical and paramedical staffs of the Department of Surgery for their constant support and guidance and data collection for this study. Without their support, this study wouldn't have completed smoothly. We also would like to acknowledge Dr. Chetan, who helped in statistical analysis.

\section{CONFLICTS OF INTERESTS}

The authors have no personal, professional, or ethical conflicts of interest in the publication of this study.

\section{REFERENCES}

1. Saurabh S, Sarkar S, Selvaraj K, Kar SS, Kumar SG, Roy G. Effectiveness of foot care education among people with type 2 diabetes in rural Puducherry, India Indian J Endocrinol Metab 2014;1:106-10. 
2. Hasnain S, Sheikh NH. Knowledge and practices regarding foot care in diabetic patients visiting the diabetic clinic in Jinnah hospital, Lahore. J Pak Med Assoc 2009;10:687-90.

3. Al-Asmary AS, Mostafa SA, Al-Khaldi YM. Diabetic patients' knowledge and practice regarding prevention of diabetic foot. Med J Cairo Univ 2013;2:197-205.

4. Bakker K, Riley P. The year of the diabetic foot. Diabetes Voice 2005;50:11-4.

5. Singh N, Armstrong DG, Lipsky BA. Preventing foot ulcers in patients with diabetes. JAMA 2007;293:217-28.

6. Pinzur MS, Slovenkai MP. Guidelines for diabetic foot care: recommendations endorsed by the diabetes committee of the American orthopaedic foot and ankle society. Foot Ankle Int 2005;26:113-9.

7. Murtaza Gondal, Uzma Bano, Shaheen Moin, Ziauddin Afridi, Rehan Masood, Anis Ahmed. Evaluation of knowledge and practices of Foot care in patients with chronic type 2 diabetes mellitus. J Postgraduate Med Institute 2007;2:104-8.

8. Cosson IC, Ney-Oliveira F, Adan LF. Evaluation of the knowledge of preventive outcomes and cost of foot ulcers in patient measures for the diabetic foot in patients of Rio Branco, Acre. Arq Bras Endocrinol Metabol 2005;4:548-56.

9. Batista F, Pinzur MS. Disease knowledge in patients attending a diabetic foot clinic. Foot Ankle Int 2005;1:38-41.

10. Shah VN, Kamdar PK, Shah N. Assessing the knowledge, attitudes and practice of type 2 diabetes among patients of
Saurashtra region, Gujarat. Int J Diabetes Dev Countries 2009;23:118-22.

11. Viswanathan V, Shobhana R, Snehalatha C, Seena R, Ramachandran A. Need for education on foot care in diabetic patients in India. J Assoc Physicians India 1999;11:1083-5.

12. Uccioli L, Faglia E, Monticone G, Favales F, Aldeghi A, Quarantiello A, et al. Manufactured shoes in the prevention of diabetic foot ulcers. Diabetes Care 1995;10:1376-8.

13. Murata GH, Shah JH, Adam KD, Wendel CS, Bukari SU, Solvas $\mathrm{PA}$, et al. Factors affecting diabetes knowledge in type 2 diabetic veterans. Diabetologia 2003;46:1170-8.

14. Desalu OO, Salawu FK, Jimoh AK, Adekoya AO, Busari OA, Olokoba AB. Diabetic foot care: Self-reported knowledge and practice among patients attending three tertiary hospitals in Nigeria. Ghana Med J 2011;45:60-5.

15. Hasnain S, Sheikh NH. Knowledge and practices regarding foot care in diabetic patients visiting the diabetic clinic in Jinnah Hospital, Lahore. J Pak Med Assoc 2009;59:687-90.

16. Al-Khaldi YM. Foot care among male diabetics in the family practice centre, Abha, Saudi Arabia. J Family Community Med 2008;15:103-6.

\section{How to cite this article}

- $\quad$ Gopal Teli, BG Ponnappa. A study on knowledge, attitudes, and practices for the prevention of diabetic foot in rural tertiary care teaching hospital. Int J Pharm Pharm Sci 2017;9(9):138-142. 